Journal of Mathematics and Statistics 8 (1): 122-128, 2012

ISSN 1549-3644

C 2012 Science Publications

\title{
Free Convection over a Permeable Horizontal Flat Plate Embedded in a Porous Medium with Radiation Effects and Mixed Thermal Boundary Conditions
}

\author{
${ }^{1}$ Mohd Zuki Salleh, ${ }^{1}$ Najihah Mohamed, \\ ${ }^{1}$ Roziena Khairuddin, ${ }^{1}$ Najiyah Safwa Khasi'ie, ${ }^{2}$ Roslinda Nazar and ${ }^{3}$ Ioan Pop \\ ${ }^{1}$ Faculty of Industrial Sciences and Technology, \\ University Malaysia Pahang 26300 UMP Kuantan, Pahang, Malaysia \\ ${ }^{2}$ School of Mathematical Sciences, Faculty of Science and Technology \\ University Kebangsaan Malaysia, 43600 UKM Bangi, Selangor, Malaysia \\ ${ }^{3}$ Faculty of Mathematics, University of Cluj, R-3400 Cluj, CP253, Romania
}

\begin{abstract}
Problem statement: In this study, the mathematical modeling of free convection boundary layer flow over a permeable horizontal flat plate embedded in a porous medium under mixed thermal boundary conditions and radiation effects is considered. Approach: The transformed boundary layer equations are solved numerically using the shooting method. Results: Numerical solutions are obtained for the wall temperature, the heat transfer coefficient, as well as the velocity and temperature profiles. The features of the flow and heat transfer characteristics for different values of the radiation parameter $\mathrm{N}_{\mathrm{R}}$, the mixed thermal boundary condition parameter $\varepsilon$ and the suction or injection parameter $\gamma$ are analyzed and discussed. Conclusion: We can conclude that when the suction or injection parameter $\gamma$ is fixed, an increase in the radiation parameter $N_{R}$ leads to the increase of $-\theta^{\prime}(0)$ (for the case of constant surface temperature). However, when $\gamma$ is fixed, an increase in $\mathrm{N}_{\mathrm{R}}$ leads to the decrease of $\theta(0)$ (for both cases of constant surface heat flux and mixed thermal boundary conditions).
\end{abstract}

Key words: Free convection, mixed thermal boundary conditions, permeable horizontal flat plate, porous medium, radiation effect

\section{INTRODUCTION}

The transport properties of fluid-saturated porous materials are due to the increasing number of important applications in many modern industries, ranging from heat removal processes in engineering technology and geophysical problems. Further examples of convection through porous media may be found in manmade systems such as granular insulations, winding structures for high-power density electric machines and the cores of nuclear reactor (Bejan, 2004; Pop and Ingham 2001; Nield et al., 2006).

Following Pop and Ingham (2001) and Ping and IDee (1976) were probably the first to consider the similarity solutions for the free convection boundary layer flow about a heated horizontal impermeable surface embedded in a porous medium, where the surface temperature is a power function of the distance from the origin. In a subsequent paper, Chang and Cheng (1983) pointed out that this boundary layer approximation is identical to the governing equations for the first order inner problem in a matched asymptotic expansion in which other effects, such as fluid entrainment, were taken into consideration. The free convection over an impermeable horizontal flat plate embedded in a porous medium has been discussed by many researchers such as Hsu et al. (1978); Ingham et al. (1985); Nazar et al. (2006) and Moghaddam et al. (2009). For permeable surfaces, Chaudhary et al. (1996) studied the natural convection from a horizontal permeable surface in a porous medium. Results obtained from various asymptotic analyses are found to compare well with those obtained from the direct numerical integration of the equations.

Radiation effects on free convection flow are important in the context of space technology and processes involving high temperature and very little is known about the effects of radiation on the boundarylayer flow of a radiating fluid past a body. The inclusion of radiation effects in the energy equation, however, leads to a highly nonlinear partial differential equation (Hossain et al., 2001). Hossain et al. (1999;

Corresponding Author: Mohd Zuki Salleh, Faculty of Industrial Sciences and Technology, University Malaysia Pahang, 26300 UMP Kuantan, Pahang Tel: +609 5492203 Fax: +609 5492276 
2001) have studied the effects of radiation on the free convection from a porous vertical plate with a uniform surface temperature, a uniform rate of suction and with variable viscosity, respectively. Recently, Bataller, (2008; Cortell 2008) separately studied radiation effects on Blasius and Sakiadis flows when the plate is maintained at a constant temperature and conjugate boundary conditions, respectively. He determined the effects of physical parameters like Prandtl number Pr and radiation parameter $\mathrm{N}_{\mathrm{R}}$ on the heat transfer characteristics. The previous studies of the free convection boundary layer flow over horizontal surfaces embedded in a porous medium dealt with numerical solutions associated with either prescribed/constant surface temperature or heat flux. Ramanaiah and Malarvizhi (1992) were the first to consider free convection adjacent to a wedge and a cone that are subjected to mixed thermal boundary conditions. On the other hand, Nazar et al. (2006) studied the free convection boundary layer flow over vertical and horizontal surfaces in a porous medium with mixed thermal boundary conditions. Laminar free convection flows about a wedge, a cone and a vertical spinning cone under mixed thermal boundary conditions and magnetic field were solved numerically using the Thomas algorithm by Ece (2005); Ece and Ozturk, 2009), respectively.

\section{MATERIALS AND METHODS}

The aim of the study is to investigate the radiation effects on free convection boundary layer flow over a horizontal flat plate embedded in a porous medium under mixed thermal boundary conditions.

Analysis: Consider the steady free convection from a horizontal flat plate embedded in a fluid-saturated porous medium of uniform temperature $\mathrm{T} \infty$. Dimensional coordinates are used with $\bar{x}$-axis measured along the surface and $\bar{y}$-axis being normal to it. The boundary layer equations which govern the steady free convection flow over a horizontal surface which is embedded in a fluid-saturated porous medium are of the following form (Pop and Ingham, 2001):

$$
\begin{aligned}
& \frac{\partial \bar{u}}{\partial \bar{x}}+\frac{\partial \bar{v}}{\partial \bar{y}}=0 \\
& \frac{\partial \bar{u}}{\partial \bar{y}}=-\frac{g K \beta}{v} \frac{\partial T}{\partial \bar{x}} \\
& \bar{u} \frac{\partial T}{\partial \bar{x}}+v \frac{\partial T}{\partial \bar{y}}=\alpha_{m} \frac{\partial^{2} T}{\partial \bar{y}^{2}}-\frac{1}{\rho c_{p}} \frac{\partial q_{r}}{\partial \bar{y}}
\end{aligned}
$$

where, $\overline{\mathrm{x}}$ and $\overline{\mathrm{y}}$ are the Cartesian coordinates with $\overline{\mathrm{x}}$ axis measured along the horizontal plate and $\bar{y}$-axis is the coordinate normal to the plate, $\mathrm{v}$ is the kinematic viscosity, $g$ is the gravitational acceleration, $\beta$ is the thermal expansion coefficient of the fluid, $\mathrm{K}$ is the permeability of the saturated porous medium, $\mathrm{T}$ is the temperature across the thermal boundary layer, $T_{\infty}$ is the constant temperature of ambient fluid, $\alpha_{\mathrm{m}}=\mathrm{k} / \rho \mathrm{c}_{\mathrm{p}}$ is the effective thermal diffusivity, $\mathrm{k}$ is the thermal conductivity, $\rho$ is the fluid density and $c_{p}$ is the specific heat of the fluid at constant pressure.

We shall solve Eq. 1-3 assuming that the boundary conditions for the velocity components $\overline{\mathrm{u}}$ and $\overline{\mathrm{y}}$ along with the mixed thermal and concentration boundary conditions are Eq. 4:

$$
\begin{aligned}
& \bar{v}(\bar{x}, 0)=v_{w}(\bar{x}) \\
& \mathrm{A}(\bar{x}) T(\bar{x}, 0)-\left.B(\bar{x}) \frac{\partial T}{\partial \bar{y}}\right|_{\bar{y}=0}=C_{1}(\bar{x}) \\
& T(\bar{x}, \bar{y}) \rightarrow T_{\infty}, \text { as } \quad \bar{y} \rightarrow \infty
\end{aligned}
$$

where, $\overline{\mathrm{v}}_{\mathrm{w}}(\overline{\mathrm{x}})$ is the mass transfer velocity with $\overline{\mathrm{v}}_{\mathrm{w}}(\overline{\mathrm{x}})>0$ when fluid is injected into the flow from the wall and $\overline{\mathrm{v}}_{\mathrm{w}}(\overline{\mathrm{x}})<0$ when fluid is removed through the wall. Let $\mathrm{A}(\overline{\mathrm{x}}), \mathrm{B}(\overline{\mathrm{x}})$ and $\mathrm{C}(\overline{\mathrm{x}})$ be the undetermined functions of $\overline{\mathrm{x}}$.

Using the Rosseland approximation for radiation (Bataller, 2008), the radiative heat flux is simplified as:

$\mathrm{q}_{\mathrm{r}}=-\frac{4 \sigma *}{3 \mathrm{k} *} \frac{\partial \mathrm{T}^{4}}{\partial \bar{y}}$

where, $\sigma^{*}$ and $\mathrm{k}^{*}$ are the Stefan-Boltzmann constant and the mean absorption coefficient, respectively. We assume that the temperature differences within the flow through the porous medium such as that the term $\mathrm{T}^{4}$ may be expressed as a linear function of temperature. Hence, expanding $\mathrm{T}^{4}$ in a Taylor series about $\mathrm{T}_{\infty}$ and neglecting higher-order terms, we get:

$\mathrm{T}^{4} \cong 4 \mathrm{~T}_{\infty}^{3} \mathrm{~T}-3 \mathrm{~T}_{\infty}^{4}$

In view of Eq. 3, 5 and 6 reduces to:

$\overline{\mathrm{u}} \frac{\partial \mathrm{T}}{\partial \overline{\mathrm{x}}}+\overline{\mathrm{v}} \frac{\partial \mathrm{T}}{\partial \overline{\mathrm{y}}}=\left(\alpha_{\mathrm{m}}+\frac{16 \sigma * \mathrm{~T}_{\infty}^{3}}{3 \rho \mathrm{c}_{\mathrm{p}} \mathrm{k}^{*}}\right) \frac{\partial^{2} \mathrm{~T}}{\partial \overline{\mathrm{y}}^{2}}$

From this equation it is seen that the effect of radiation is to enhance the thermal diffusivity. Following Bataller (2008), we take $\mathrm{N}_{\mathrm{R}}=\mathrm{kk} * /\left(4 \sigma^{*} \mathrm{~T}_{\infty}{ }^{3}\right)$ as the radiation parameter, so that Eq. 7 becomes: 
$\overline{\mathrm{u}} \frac{\partial \mathrm{T}}{\partial \overline{\mathrm{x}}}+\overline{\mathrm{v}} \frac{\partial \mathrm{T}}{\partial \overline{\mathrm{y}}}=\frac{\alpha_{\mathrm{m}}}{\mathrm{k}_{0}} \frac{\partial^{2} \mathrm{~T}}{\partial \overline{\mathrm{y}}^{2}}$

where the dimensionless parameter $\mathrm{k}_{0}$ is defined as:

$\mathrm{k}_{0}=\frac{3 \mathrm{~N}_{\mathrm{R}}}{3 \mathrm{~N}_{\mathrm{R}}+4}$

Further, we introduce now, the following dimensionless variables Eq. 9 and 10:

$$
\begin{aligned}
\mathrm{x} & =\overline{\mathrm{x}} / \mathrm{L}, \quad \mathrm{y}=\mathrm{Ra}^{1 / 3}(\overline{\mathrm{y}} / \mathrm{L}) \\
\mathrm{u} & =\mathrm{Ra}^{-2 / 3}\left(\mathrm{~L} / \alpha_{\mathrm{m}}\right) \overline{\mathrm{u}} \\
\mathrm{v} & =\mathrm{Ra}^{-1 / 3}\left(\mathrm{~L} / \alpha_{\mathrm{m}}\right) \overline{\mathrm{v}} \\
\theta & =\left(\mathrm{T}-\mathrm{T}_{\infty}\right) /\left(\mathrm{T}_{\mathrm{r}}-\mathrm{T}_{\infty}\right)
\end{aligned}
$$

where, $\mathrm{T}_{\mathrm{r}}$ is the reference temperature and $\mathrm{Ra}=\mathrm{gK} \beta\left(\mathrm{T}_{\mathrm{r}}-\mathrm{T}_{\infty}\right) \mathrm{L} / \alpha_{\mathrm{m}} \mathrm{v}$ is the Rayleigh number for a porous medium Thus, Eq. 1, 2 and 8 can be written as:

$$
\frac{\partial u}{\partial x}+\frac{\partial v}{\partial y}=0
$$

$\frac{\partial u}{\partial y}=-\frac{\partial \theta}{\partial x}$

$\mathrm{u} \frac{\partial \theta}{\partial \mathrm{x}}+\mathrm{v} \frac{\partial \theta}{\partial \mathrm{y}}=\frac{1}{\mathrm{k}_{0}} \frac{\partial^{2} \theta}{\partial \mathrm{y}^{2}}$

And the boundary conditions (4) become:

$$
\begin{aligned}
& \mathrm{v}(\mathrm{x}, 0)=\mathrm{v}_{\mathrm{w}}(\mathrm{x}) \\
& \mathrm{A}(\mathrm{x})\left(\mathrm{T}_{\mathrm{r}}-\mathrm{T}_{\infty}\right) \theta(\mathrm{x}, 0) \\
& \quad-\left.\mathrm{B}(\mathrm{x})\left(\mathrm{T}_{\mathrm{r}}-\mathrm{T}_{\infty}\right) \frac{\mathrm{Ra}^{1 / 3}}{\mathrm{~L}} \frac{\partial \theta}{\partial \mathrm{y}}\right|_{\mathrm{y}=0}=\mathrm{C}(\mathrm{x}) \\
& \theta(\mathrm{x}, \mathrm{y}) \rightarrow 0 \text { as } \mathrm{y} \rightarrow \infty
\end{aligned}
$$

We look for a similarity solution of Eq. 11-15 of the following form:

$$
\begin{aligned}
& \psi=x^{1 / 3} f(\eta), \quad \theta=\theta(\eta) \\
& \eta=y / x^{2 / 3}
\end{aligned}
$$

where, $\Psi$ is the stream function defined in the usual way as $\mathrm{u}=\partial \psi / \partial \mathrm{y}$ and $\mathrm{v}=-\partial \psi / \partial \mathrm{x}$, which identically satisfy Eq. 11. In order that similarity solution exists, we assume that $\mathrm{v}_{\mathrm{w}}(\mathrm{x})=(2 / 3) \mathrm{x}^{-1 / 3} \gamma$, where $\gamma>0$ is for injection and $\gamma>0$ is for withdrawal of fluid. Substituting 15 into Eq. 12 and 13, we obtain the following ordinary differential equations:

$\mathrm{f}^{\prime \prime}-\frac{2}{3} \eta \theta^{\prime}=0$

$\theta^{\prime \prime}+\frac{1}{3} \mathrm{k}_{0}$ f $\theta^{\prime}=0$

where primes denote differentiation with respect to $\eta$. It is worth mentioning here that when $\mathrm{k}_{0}=1$, the thermal radiation effect is not considered. The boundary conditions (14) reduce to Eq. 18 and 19:

$\mathrm{f}(0)=-\gamma$
$\mathrm{a}(\mathrm{x})\left(\mathrm{T}_{\mathrm{r}}-\mathrm{T}_{\infty}\right) \theta(0)-\mathrm{b}(\mathrm{x})\left(\mathrm{T}_{\mathrm{r}}-\mathrm{T}_{\infty}\right)^{4 / 3} \theta^{\prime}(0)=1$
$\mathrm{f}^{\prime}(\infty) \rightarrow 0, \quad \theta(\infty) \rightarrow 0$ as $\eta \rightarrow \infty$

Where:

$$
\begin{aligned}
& a(x)=\frac{A(x)}{C(x)} \\
& b(x)=\frac{B(x)}{C(x)} x^{-2 / 3}\left(\frac{g K \beta}{\alpha_{m} v L}\right)^{1 / 3}
\end{aligned}
$$

Each of these functions $a(x)$ and $b(x)$ must be equal to a constant to enable a similarity solution. For given values of the constants $a, b$ and $T_{\infty}$, the reference temperature $T_{r}$ may be chosen to satisfy the following equation without any loss of generality Eq. 20:

$\mathrm{a}\left(\mathrm{T}_{\mathrm{r}}-\mathrm{T}_{\infty}\right)+\mathrm{b}\left(\mathrm{T}_{\mathrm{r}}-\mathrm{T}_{\infty}\right)^{4 / 3}=1$

By defining $\xi=\mathrm{b}\left(\mathrm{T}_{\mathrm{r}}-\mathrm{T}_{\infty}\right)^{4 / 3}$, the thermal boundary conditions (18) can be written as Eq. 21:

$(1-\xi) \theta(0)-\xi \theta^{\prime}(0)=1$

It is worth noticing that the case $\xi=0$ corresponds to the constant surface temperature (CWT) $\theta(0)=1$, the case $\xi=1$ corresponds to the constant surface heat flux $(\mathrm{CHF}) \theta^{\prime}(0)=-1$ and the case $\xi=\infty$ corresponds to the mixed thermal boundary conditions (MBC).

\section{RESULTS AND DISCUSSION}

Equation 16 and 17 subject to boundary conditions 18 are solved numerically using the shooting method for the cases of CWT when $\xi=0, \mathrm{CHF}$ when $\xi=1$ and MBC when $\xi=\infty$. Values of $\gamma$ considered are $\gamma=-1<0$ (suction), $\gamma=0$ (impermeable wall) and $\gamma=1>0$ (injection). 
J. Math. \& Stat., 8 (1): 122-128, 2012

Table 1: Values of $-\theta^{\prime}(0)$ when $\gamma=0, \mathrm{k}_{0}=1$ (the thermal radiation effect is not considered) and $\xi=0$ (CWT case)

\begin{tabular}{|c|c|c|c|}
\hline \multicolumn{4}{|c|}{$\xi=0(\mathrm{CWT})-\theta^{\prime}(0) \mathrm{s}$} \\
\hline \multicolumn{3}{|c|}{ Chang and Cheng (1983) } & Present \\
\hline \multicolumn{3}{|c|}{0.4299} & 0.4300 \\
\hline \multicolumn{4}{|c|}{$\begin{array}{l}\text { Table 2: Values of }-\theta^{\prime}(0) \text { for various values of } N_{R} \text { when } \xi=0 \\
(\mathrm{CWT}) \text { and } \gamma=-1,0 \text { and } 1\end{array}$} \\
\hline$\underline{N_{R}}$ & $\begin{array}{l}\gamma=-1 \\
\text { (suction) }\end{array}$ & $\begin{array}{l}\gamma=0 \\
\text { (impermeable wall) }\end{array}$ & $\begin{array}{l}\gamma=1 \\
\text { (injection) }\end{array}$ \\
\hline 0.1 & 0.1887 & 0.1766 & 0.1656 \\
\hline 0.5 & 0.3267 & 0.2786 & 0.2360 \\
\hline 1 & 0.4008 & 0.3242 & 0.2584 \\
\hline 3 & 0.5074 & 0.3798 & 0.2773 \\
\hline 7 & 0.5619 & 0.4053 & 0.2824 \\
\hline 10 & 0.5771 & 0.4121 & 0.2834 \\
\hline 100 & 0.6138 & 0.4278 & 0.2854 \\
\hline 1000 & 0.6180 & 0.4295 & 0.2855 \\
\hline
\end{tabular}

Table 3: Values of $\theta(0)$ for various values of $\mathrm{N}_{\mathrm{R}}$ when $\xi=1$ (CHF) and $\gamma=-1,0$ and 1

\begin{tabular}{llll}
\hline $\mathrm{N}_{\mathrm{R}}$ & $\begin{array}{l}\gamma=-1 \\
\text { (suction) }\end{array}$ & $\begin{array}{l}\gamma=0 \\
\text { (impermeable wall) }\end{array}$ & $\begin{array}{l}\gamma=1 \\
\text { (injection) }\end{array}$ \\
\hline 0.1 & 3.5514 & 3.6668 & 3.7826 \\
0.5 & 2.3831 & 2.6061 & 2.8434 \\
1 & 2.0525 & 2.3286 & 2.6295 \\
3 & 1.7220 & 2.0646 & 2.4579 \\
7 & 1.5936 & 1.9669 & 2.4038 \\
10 & 1.5613 & 1.9429 & 2.3917 \\
100 & 1.4887 & 1.8891 & 2.3667 \\
1000 & 1.4810 & 1.8835 & 2.3642 \\
\hline
\end{tabular}

Table 4: Values of $\theta(0)$ for various values of $N_{R}$ when $\xi=\infty$ (MBC) and $\gamma=-1,0$ and 1

\begin{tabular}{lrlr}
\hline $\mathrm{N}_{\mathrm{R}}$ & $\begin{array}{l}\gamma=-1 \\
\text { (suction) }\end{array}$ & $\begin{array}{l}\gamma=0 \\
\text { (impermeable wall) }\end{array}$ & $\begin{array}{l}\gamma=1 \\
\text { (injection) }\end{array}$ \\
\hline 0.1 & 173.8079 & 180.0499 & 186.3511 \\
0.5 & 39.9806 & 46.0506 & 52.4915 \\
1 & 23.3410 & 29.3049 & 35.8520 \\
3 & 12.3566 & 18.1411 & 24.8680 \\
7 & 9.2675 & 14.9515 & 21.7791 \\
10 & 8.5786 & 14.1338 & 21.0904 \\
100 & 7.1427 & 12.7267 & 19.5120 \\
1000 & 7.0000 & 12.5760 & 19.5120 \\
\hline
\end{tabular}

Table 1 shows the numerical values of $-\theta^{\prime}(0)$ when $\xi=$ 0 (CWT case) with $\gamma=0$ and $\mathrm{k}_{0}=1$, where the thermal radiation effect is not considered.
Table 5: Values of $\mathrm{f}^{\prime}(0)$ for various values of $\mathrm{N}_{\mathrm{R}}$ when $\xi=\infty$ (MBC) and $\gamma=-1,0$ and 1

\begin{tabular}{|c|c|c|c|}
\hline $\mathrm{N}_{\mathrm{R}}$ & $\begin{array}{l}\gamma=-1 \\
\text { (suction) }\end{array}$ & $\begin{array}{l}\gamma=0 \\
\text { (impermeable wall) }\end{array}$ & $\begin{array}{l}\gamma=1 \\
\text { (injection) }\end{array}$ \\
\hline 0.1 & 79.4118 & 81.7598 & 84.1261 \\
\hline 0.5 & 18.5942 & 20.9153 & 23.3079 \\
\hline 1 & 11.0096 & 13.3097 & 15.7222 \\
\hline 3 & 5.9752 & 8.2394 & 10.6853 \\
\hline 7 & 4.5470 & 6.7907 & 9.2551 \\
\hline 10 & 4.2269 & 6.4647 & 8.9344 \\
\hline 100 & 3.5571 & 5.7802 & 8.2628 \\
\hline 1000 & 3.4903 & 5.7118 & 8.1958 \\
\hline
\end{tabular}

The numerical result obtained by an implicit finitedifference scheme as reported by Chang and Cheng (1983) for the case of CWT is included in this table for comparison purposes. It is found that the agreement between the previously published results with the present one is very good. We can conclude that this numerical method works efficiently for the present problem and we are also confident that the results presented here are accurate.

Values of $-\theta^{\prime}$ ( $(0)$ for various values of $\mathrm{N}_{\mathrm{R}}$ when $\xi=$ 0 (for the case of CWT) and $\gamma=-1,0$ and 1 are presented in Table 2. It is observed that $-\theta^{\prime}$ (0) increases with increasing the radiation parameter $\mathrm{N}_{\mathrm{R}}$ for all cases of $\gamma=-1,0$ and 1 . When $N_{R}$ is fixed, it can be seen that $-\theta^{\prime}(0)$ is higher for and $\gamma=-1<0$ (suction) rather than those for $\gamma=0$ and $\gamma=1>0$ (injection).

Table 3 presents the values of $\theta(0)$ for various values of $\mathrm{N}_{\mathrm{R}}$ when $\xi=1$ (for the case of CHF) and $\gamma=$ 1,0 and 1 . It is found that $\theta(0)$ decreases with increasing the radiation parameter $\mathrm{N}_{\mathrm{R}}$ for all cases of $\gamma$ $=-1,0$ and 1. For fixed $N_{R}$, it can be seen that $\theta(0)$ is lower for $\gamma=-1<0$ (suction) rather than those for $\gamma=0$ and $\gamma=1>0$ (injection).

Table 4 and 5 present the values of $\theta(0)$ and f' $(0)$, respectively, for various values of $N_{R}$ when $\xi=\infty$ (MBC) and $\gamma=-1,0$ and 1. It is found that both $\theta(0)$ and f' (0) decrease with increasing the radiation parameter $\mathrm{N}_{\mathrm{R}}$ for all cases of $\gamma=-1,0$ and 1 . For fixed $\mathrm{N}_{\mathrm{R}}$, it can be seen that $\theta(0)$ and $\mathrm{f}^{\prime}(0)$ is lower for $\gamma=-1<0$ (suction) rather than those for $\gamma=0$ and $\gamma=1<0$ (injection).

The trend for MBC case is similar to the CHF case but different from the CWT case. It is worth mentioning that the numerical values given in Table 1-5 are very important and they serve as a reference against which other exact or approximate solutions can be compared in the future. 


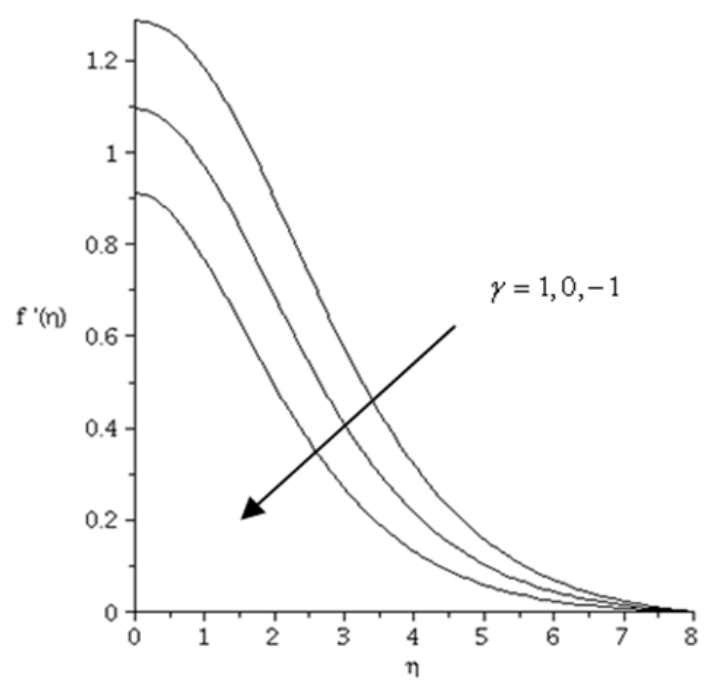

Fig. 1: Velocity profiles when and (CWT case)

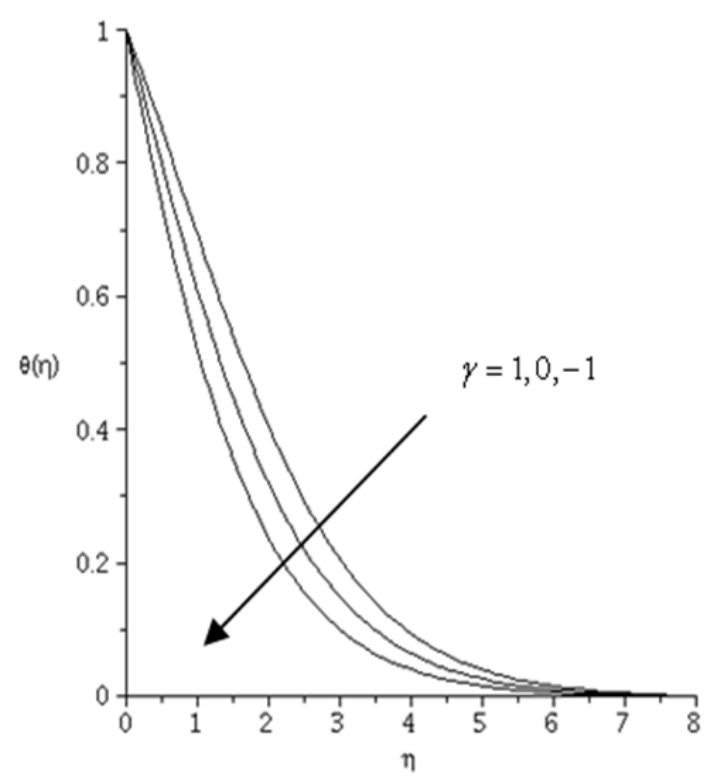

Fig. 2: Temperature profiles when and (CWT case)

Figure 1-6 illustrate the velocity and temperature profiles when $\mathrm{N}_{\mathrm{R}}=10, \xi=0$ (CWT), $\xi=1$ (CHF) and $\xi$ $=\infty(\mathrm{MBC})$, respectively. These figures show that the values of $f^{\prime}(\eta)$ and $\theta(\eta)$ decrease from 1 to 0 as $\eta$ increases from zero at different values of $\gamma$. Also, it is noticed that as $\gamma$ decreases, both the velocity and temperature profiles decrease and also the thermal boundary layer thickness decreases.

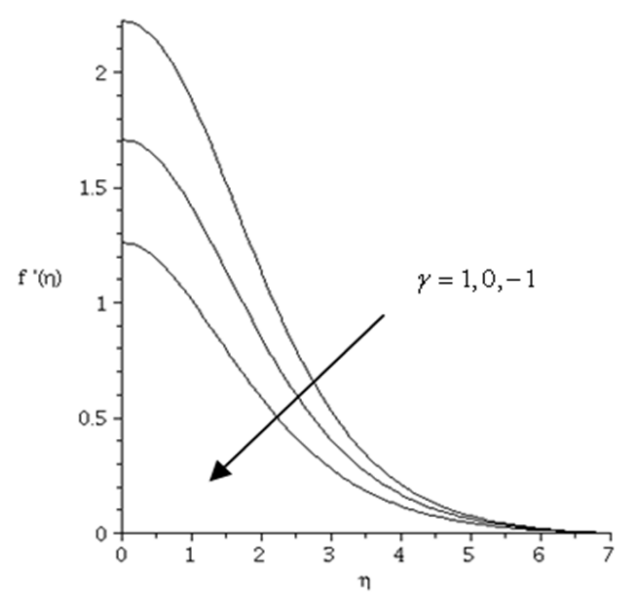

Fig. 3: Velocity profiles when and (CHF case)

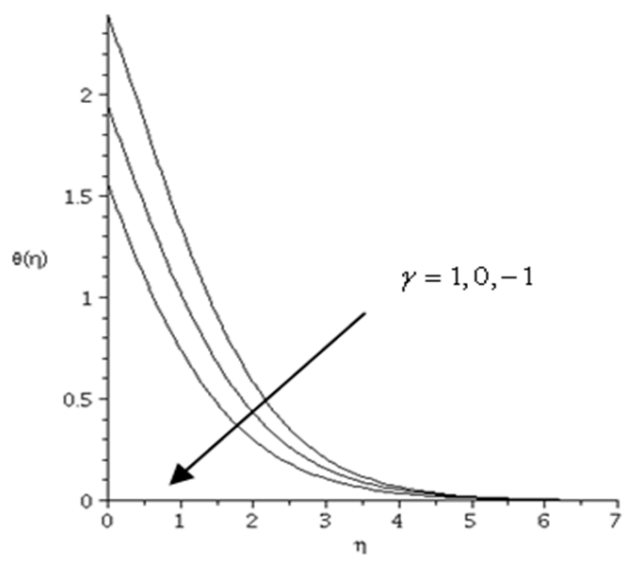

Fig. 4: Temperature profiles when and (CHF case)

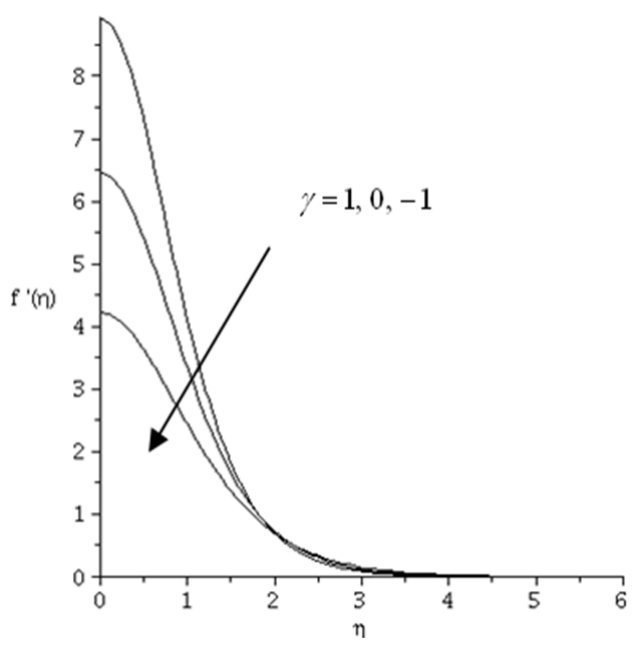

Fig. 5: Velocity profiles when $\mathrm{NR}=10$ and (MBC case) 


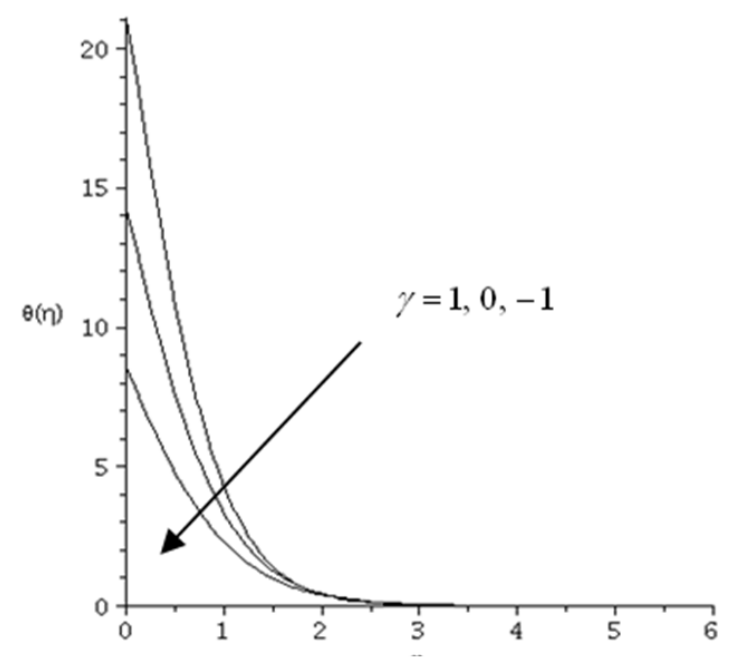

Fig. 6: Temperature profiles when and (MBC case)

\section{CONCLUSION}

In this study, we have numerically studied the problem of free convection over a permeable horizontal flat plate embedded in a porous medium under mixed thermal boundary conditions with thermal radiation effects. We can conclude that when $\gamma$ is fixed, an increase in the radiation parameter $N_{R}$ leads to the increase of $-\theta^{\prime}$ ( 0 ) (for the case of CWT). But, when $\gamma$ is fixed, an increase in the radiation parameter $\mathrm{N}_{\mathrm{R}}$ leads to the decrease of $\theta(0)$ (for both cases of CHF and MBC).

\section{ACKNOWLEDGEMENT}

The authors gratefully acknowledge the financial supports received from the Ministry of Higher Education, Malaysia (UKM-ST-07-FRGSS0036-2009) and a research grant (RDU090308) from the Universiti Malaysia Pahang.

\section{REFERENCES}

Bataller, R.C., 2008. Radiation effects in the blasius flow. Applied Math. Comput. 198: 333-338. DOI: 10.1016/j.amc.2007.08.037

Bejan, A., 2004. Convection Heat Transfer. 3rd Edn., Wiley, Adrian Bejan, ISBN-10: 0471271500 pp: 694.

Chang, I.D. and P. Cheng, 1983. Matched asymptotic expansions for free convection about an impermeable horizontal surface in a porous medium. Int. J. Heat Mass Transfer, 26: 163-173. DOI: $10.1016 / \mathrm{S} 0017-9310(83) 80023-4$
Chaudhary, M.A., J.H. Merkin and I. Pop, 1996. Natural convection from a horizontal permeable surface in a porous medium-numerical and asymptotic solutions. Trans. Porous Media, 22: 327-344. DOI: $10.1007 / \mathrm{BF} 00161630$

Cortell, R., 2008. A numerical tackling on Sakiadis flow with thermal radiation. Chin. Phys. Lett. 25: 1340-1342. DOI: $10.1088 / 0256-307 X / 25 / 4 / 048$

Ece, M.C. and A. Ozturk, 2009. Boundary-layer flow about a vertical spinning cone under mixed thermal boundary conditions and a magnetic field. Meccanica, 44: 177-187. DOI: 10.1007/s11012008-9159-х

Ece, M.C., 2005. Free-convection flow about a wedge under mixed thermal boundary conditions and a magnetic field. Heat Mass Transfer, 41: 291-297. DOI: 10.1007/s00231-004-0531-7

Hossain, M.A., K. Khanafer and K. Vafai, 2001. The effect of radiation on free convection flow of fluid with variable viscosity from a porous vertical plate. Int. J. Thermal Sci. 40: 115-124.

Hossain, M.A., M.A. Alim and D.A.R. Rees 1999. The effect of radiation on free convection from a porous vertical plate. Int. J. Heat Mass Transfer, 42: 181-191. DOI: 10.1016/S0017-9310(98)00097-0

Hsu, C.T., C. Ping and G.M. Homsy, 1978. Instability of free convection flow over a horizontal impermeable surface in a porous medium. Int. J. Heat Mass Transfer, 21: 1221-1228. DOI: 10.1016/0017-9310(78)90141-2

Ingham, D.B., J.H. Merkin and I. Pop, 1985. Flow past a suddenly cooled horizontal flat surface in a saturated porous medium. Acta Mech., 56: 205217. DOI: $10.1007 / \mathrm{BF} 01177118$

Moghaddam, M.M., H.R. Ghazizadeh and A. Mansouri, 2009. Homotopy analysis solution of free convection flow on a horizontal impermeable surface embedded in a saturated porous medium. Commun. Nonlinear Sci. Numer. Simulat. 14: 3833-3843. DOI: 10.1016/j.cnsns.2008.09.004

Nazar, R., N.M. Arifin and I. Pop, 2006. Free convection boundary layer flow over vertical and horizontal flat plates embedded in a porous medium under mixed thermal boundary conditions. Int. Commun. Heat Mass Transfer, 33: 87-93. DOI: 10.1016/j.icheatmasstransfer.2005.09.003

Nield, D.A., A. Bejan and N. Bejan, 2006. Convection in Porous Media. 3rd Edn., Springer, New York, ISBN-10: 0387290966 pp: 640.

Ping, C. and C. I-Dee, 1976. Buoyancy induced flows in a saturated porous medium adjacent to impermeable horizontal surfaces. Int. J. Heat Mass Transfer, 19: 1267-1272. DOI: 10.1016/00179310(76)90078-8 
Pop, I. and D.B. Ingham, 2001. Convective Heat Transfer: Mathematical and Computational Modelling of Viscous Fluids and Porous Media. 1st Edn., Elsevier, New York, ISBN: 0080438784 pp: 652.
Ramanaiah, G. and G. Malarvizhi, 1992. Free convection about a wedge and a cone subjected to mixed thermal boundary conditions. Acta. Mech. 93: 119-123. DOI: 10.1007/BF01182577 